\title{
PENGARUH KINERJA BRAND EQUITY DAN TRUST TERHADAP CUSTOMER LOYALTY \\ (Survei kepada Pelanggan Alat Berat Excavator merek Kobelco di Kota Bandung )
}

\author{
Hilmi Muttaqien \\ Universitas Pendidikan Indonesia \\ hilmimuttaqien@gmail.com \\ Ratih Hurriyati \\ Universitas Pendidikan Indonesia \\ ratih@upi.edu
}

\begin{abstract}
ABSTRAK
Persaingan yang kompetitif di industri alat berat yang ditandai dengan turunnya loyalitas pelanggan. Loyalitas pelanggan menjadi suatu hal yang tidak bisa diabaikan begitu saja dalam sebuah perusahaan. Solusi utama yang harus dilakukan perusahaan adalah dengan meningkatkan loyalitas pelanggan dan mempertahankan hidup perusahaannya dengan cara berbagai strategi salah satunya brand equity dan trust. Penelitian ini bertujuan untuk mengetahui gambaran tingkat brand equity pada pengguna alat berat excavator merek Kobelco di Kota Bandung, mengetahui gambaran tingkat trust pada pengguna alat berat excavator merek Kobelco di Kota Bandung, mengetahui gambaran tingkat customer loyalty pada pengguna alat berat excavator merek Kobelco di Kota Bandung, dan memperoleh temuan besarnya pengaruh brand equity dan trust terhadap tingkat customer loyalty pada pengguna alat berat excavator merek Kobelco di Kota Bandung. Jenis penelitian yang digunakan adalah deskriptif verifikatif, dan metode yang digunakan adalah explanatory survey dengan teknik uji populasi dengan jumlah populasi sebanyak 35 perusahaan pengguna alat berat sebagai responden. Teknik analisis data yang digunakan adalah Partial Least Square dengan alat bantu software komputer SmartPLS 3.0. Berdasarkan hasil penelitian secara keseluruhan nilai perhitungan yang diperoleh melalui Partial Least Square lebih besar dibandingkan dengan yang terdapat pada tabel. Artinya secara keseluruhan terdapat pengaruh yang signifikan dari brand equity dan trust terhadap customer loyalty. Dalam upaya meningkatkan loyalitas pelanggan, pihak perusahaan harus senantiasa meningkatkan kepercayaan pelanggan terhadap perusahaan. Brand equity dan trustsebagai variabel yang berpengaruh dominan harus tetap dapat dikendalikan secara langsung oleh perusahaan.
\end{abstract}

Kata Kunci: Brand Equity, Trust, Customer Loyalt ABSTRACT

Competitive competition in the heavy equipment industry are characterized by the decline in customer loyalty. Customer loyalty becomes a thing that can not be ignored in a company. The main solution to do the company is to increase customer loyalty and maintain its life by way of various strategies one brand equity and trust. This study aims to level overview on brand equity heavy equipment excavators brand Kobelco in Bandung, level overview on trust heavy equipment excavators brand Kobelco in Bandung, level overview on customer loyalty in the heavy equipment excavators brand Kobelco in Bandung and determine how much influence the findings brand equity and trust toward customer loyalty to the brand Kobelco excavator heavy equipment in Bandung. This type of research is descriptive verification, and the method used is explanatory survey population testing techniques with a total population of 35 companies users of heavy equipment as respondents. The data analysis technique used is Partial Least Square with computer software tools SmartPLS 3.0. Based on the research results overall value estimates obtained through Partial Least Square greater than that contained in the table. It means that overall there is significant influence of brand equity and trust on customer loyalty. In an effort to increase customer loyalty, the company must continually improve customer confidence in the company. Brand equity and trust a variables should remain the dominant influence can be controlled directly by the company.

\section{PENDAHULUAN}

Sektor industri di Indonesia saat ini, menjadi pusat dari pembangunan dan perekonomian bangsa. Hal ini menunjukkan semakin meningkatnya peranan industri, persaingan menjadi hal yang sangat mempengaruhi kelangsungan hidup perusahaan. Sasaran strategi utama adalah pemenuhan kebutuhan konsumen secara tepat, baik dari sisi waktu dan dari sisi jumlah demi menjaga loyalitas konsumen. 
Bisnis alat berat merupakan bagian yang tidak terpisahkan dari usaha proyek pembangunan, pertambangan, infrastruktur, dan usaha agroindustri. Karena alat berat sebagai alat pendukung bahkan alat utama dalam sebuah proyek pertambangan, infrastruktur, dan agroindustri. Berdasarkan hasil penelitian Himpunan Industri Alat Berat mengemukakan pertumbuhan industri alat berat pada tahun 2014 mengalami penurunan yang cukup signifikan sejak tahun 2012, hal tersebut diindikasikan karena permintaan alat berat diberbagai sektor seperti (konstruksi, pertambangan, dan agro industri) mengalami penurunan. Menurut hasil laporan indoanalisis, bahwa pertumbuhan alat berat hanya mencapai 13.300 unit, dibandingkan dengan 3 tahun terdahulu, dimana tahun 2011 pertumbuhan alat berat hingga mencapai 17.360 unit.

Penurunan pertumbuhan terhadap alat berat di Indonesia pada tahun ini menurun cukup signifikan. Kondisi ini berdampak kepada para pemain industri alat berat di Indonesia, khususnya dimana merekmerek besar alat berat di Indonesia seperti Komatsu, Caterpillar, Kobelco, dan Hitachi mengalami penurunan di seluruh merek alat berat tersebut selama 3 tahun sejak tahun 2011-2014. Indikasi penurunan market share pada industri alat berat menunjukan permasalahan pada rendahnya tingkat loyalitas konsumen alat berat excavator khususnya merek Kobelco di Indonesia.

Penurunan loyalitas konsumen alat berat juga terjadi di beberapa kota besar di Provinsi Jawa Barat. Permasalahan tersebut terjadi juga di Kota Bandung, berdasarkan hasil survei pada perusahaan CV. Bandung Jaya Diesel sebagai salah satu perusahaan yang bergerak dibidang distributor spare parts alat berat di Kota Bandung, dengan melakukan wawancara kepada General Manager CV. Bandung Jaya Diesel mengenai perkembangan alat berat excavator di Kota Bandung.

Hasil wawancara tersebut menunjukkan bahwa merek-merek alat berat excavator di Kota Bandung juga mengalami penurunan loyalitas yang cukup signifikan. Khususnya loyalitas konsumen alat berat excavator pada merek Kobelco yang penggunanya relatif lebih sedikit dibandingkan dengan alat berat merek Komatsu, Hitachi dan Caterpillar. Alat berat merek Kobelco masih berada di bawah merek Komatsu, Hitachi dan Caterpillar, sehingga kedua merek tersebut perlu melakukan strategi untuk mengalahkan pesaingnya dari segi merek, nilai produk, kepuasan konsumen, pelayanan, kepercayaan konsumen dan lainnya.
Berdasarkan hasil wawancara jika alat berat excavator merek Kobelco tidak melakukan strategi yang tepat, maka alat berat excavator merek Kobelco akan terus mengalami penurunan loyalitas konsumennya dan tidak akan bisa bersaing dengan para pesaingnya yaitu alat berat excavator merek Komatsu, Caterpillar dan Hitachi. Kondisi ini akan berdampak pada perusahaan alat berat Kobelco akan terus mengalami penurunan loyalitas konsumennya, disebabkan oleh kurang tepatnya strategi yang dilakukan perusahaan tersebut untuk meningkatkan loyalitas konsumennya. Perusahaan alat berat merek Kobelco harus menggunakan strategi yang tepat untuk meningkatkan loyalitas konsumennya.

Strategi yang dilakukan oleh para pengusaha alat berat tersebut bertujuan untuk meningkatkan loyalitas konsumen pada merek alat berat khususnya alat berat merek Kobelco. Seperti menurut penelitian yang dilakukan oleh Steven A. Taylor, Kevin Geluch and Stephen Goodwin (2004:217) mengemukakan bahwa "The importance of brand equity to customer loyalty, this study involved a nation-wide sample of industrial customers of heavy equipment manufacturers." Pentingnya Brand Equity terhadap Customer Loyalty, survey dilakukan kepada sample konsumen industri manufaktur alat berat di USA.

Pada penelitian ini juga ditemukan temuan bahwa Brand Equity berpengaruh positif pada Customer Loyalty heavy equipment, dan Trust berpengaruh positif terhadap Customer Loyalty heavy equipment. Menurut penelitian ini ada beberapa faktor yang mempengaruhi customer loyalty heavy equipment yaitu: Satisfaction, Value, Resistance to change, Brand affect, Trust, and Brand Equity. Bersumber dari penelitian tersebut bahwa ada beberapa faktor yang mempengaruhi loyalitas konsumen alat berat, diantara beberapa faktor yang mempengaruhi loyalitas konsumen alat berat dan disesuaikan dengan strategi perusahan alat berat Kobelco yaitu menggunakan strategi Brand Equity dan Trust untuk meningkatan loyalitas konsumen alat berat.

Menurut penilitian Richard L. Oliver (2008:391) bahwa "Customer loyalty is a deeply held commitment to rebuy or repatronize a preferred product or service consistently in the future, despite situational influences and marketing efforts having the potential to cause switching behavior." Loyalitas pelanggan adalah suatu komiten yang sangat dipegang teguh untuk membeli atau melakukan pembelian ulang akan produk atau jasa secara konsisten di masa depan, walaupun adanya pengaruh situasional dan adanya 
upaya pemasaran untuk menyebabkan pelanggan berpindah.

Kotler dan Amstrong

(2014:266) mendefinisikan brand equity is the differential effect that knowing the brand name has on customer response to the product and its marketing. Ekuitas merek adalah efek diferensial yang mengetahui nama merek telah di respon pelanggan terhadap produk dan pemasaran. Menurut penelitian Elena Delgado Ballester (2014:11) mendefinisikan Brand Trust is Feeling of security held by the consumer in his/her interaction with the brand, that it is based on the perceptions that the brand is reliable and responsible for the interests and welfare of the consumer. Perasaan keamanan yang diselenggarakan oleh konsumen yang langsung interaksinya dengan merek itu sendiri, sehingga hal itu didasarkan pada persepsi bahwa merek adalah terpercaya dan bertanggung jawab untuk kepentingan dan kesejahteraan konsumen.

Berdasarkan latar belakang tersebut, peneliti merasa perlu melakukan penelitian dengan judul "Pengaruh kinerja Brand Equity dan Trust terhadap Customer Loyalty ( Survei pada konsumen alat berat Excavator Merek Kobelco di Kota Bandung )

Adapun Penelitian ini dimaksudkan untuk memperoleh temuan mengenai pengaruh kinerja brand equity dan trust terhadap customer loyalty pengguna alat berat excavator merek Kobelco di Kota Bandung.

\section{METODE PENELITIAN}

Unit analisis yang dijadikan responden dalam penelitian ini adalah konsumen pengguna alat berat excavator merek Kobelco di Kota Bandung. Oleh karena itu akan diteliti pengaruh kinerja brand equity dan trust terhadap customer loyalty pada konsumen pengguna alat berat excavator merek Kobelco di Kota Bandung. Penelitian ini dilakukan dalam kurun waktu kurang dari satu tahun, maka metode yang digunakan adalah cross sectional method, pengumpulan informasi dari subjek penelitian hanya dilakukan satu kali dalam satu periode waktu, sehingga penelitian ini merupakan cross sectional. Penelitian ini dilakukan pada bulan Juni hingga November 2015. Populasi dalam penelitian ini adalah konsumen pengguna alat berat excavator merek Kobelco di Kota Bandung pada tahun 2014-2015 sebanyak N: 35 Perusahaan. Pengambilan sampling menggunakan sampel jenuh atau pengambilan populasi karena N kurang dari 100 .

\section{HASIL PENELITIAN DAN PEMBAHASAN}

Hasil pengujian antar variabel $\mathrm{X}_{1}$ dan $\mathrm{X}_{2}$ terhadap Y secara keseluruhan memberikan hasil yang signifikan. Maka untuk mengetahui variabel eksogen mana yang secara individual berpengaruh signifikan terhadap variabel endogen. Pengujian yang digunakan dalam penelitian ini menggunakan Partial Least Square Path Modeling. Besarnya kontribusi variabel Kinerja brand equity dan Trust terhadap Customer loyalty dapat dilihat dari nilai koefisien jalurnya.

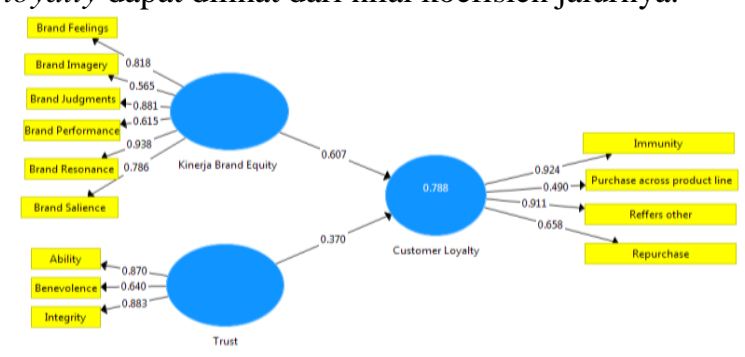

Keterangan :

$\mathrm{X}_{1}$ : Kinerja Brand Equity

$\mathrm{X}_{2}$ : Trust

Y : Customer Loyalty

\section{GAMBAR 1}

\section{DIAGRAM JALUR KINERJA BRAND EQUITY DAN TRUST TERHADAP CUSTOMER LOYALTY}

Berdasarkan Gambar 1 menunjukan koefisien jalur seluruh model indikator dari setiap variabel Kinerja brand equity, Trust, dan Customer loyalty berpengaruh positif terhadap variabelnya karena telah memenuhi convergent validity berada di atas atau sama dengan 0,5

Hal ini sesuai dengan yang diungkapkan oleh Steven A. Taylor, Kevin Geluch and Stephen Goodwin (2004:217) mengemukakan bahwa "The importance of brand equity and trust to customer loyalty, this study involved a nation-wide sample of industrial customers of heavy equipment manufacturers." Pentingnya Brand Equity dan trust terhadap Customer Loyalty, survey dilakukan kepada sample konsumen industri manufaktur alat berat di USA. Pada penelitian ini juga ditemukan temuan bahwa Brand Equity dan Trust berpengaruh positif pada Customer Loyalty heavy equipment.

\section{KESIMPULAN DAN REKOMENDASI Kesimpulan}

Berdasarkan hasil penelitian yang telah dilakukan menggunakan analisis deskriptif dan verifikatif dengan menggunakan teknik analisis Partial Least Square- Path Modeling (PLS-PM) antara kinerja brand equity dan trust terhadap customer loyalty (survei kepada pengguna alat berat excavator merek kobelco di Kota Bandung) maka berdasarkan penelitian tersebut dapat diambil kesimpulan sebagai berikut:

Variabel kinerja brand equity dan trust memiliki pengaruh yang positif dan signifikan terhadap customer loyalty dengan pengaruh yang cukup tinggi dari kedua variabel tersebut untuk mempengaruhi konsumen dalam menggunakan dan mempertahankan suatu produk. Hal ini menunjukkan bahwa semakin baik perusahaan membangun program kinerja brand equity dan trust kepada konsumennya maka akan 
semakin baik juga customer loyalty terhadap alat berat excavator merek kobelco.

\section{Rekomendasi}

Hasil penelitian menyatakan kinerja brand equity dan trust berpengaruh secara positif dalam meningkatkan customer loyalty pengguna alat berat excavator merek kobelco di Kota Bandung, maka penulis merekomendasikan agar perusahaan alat berat Kobelco dapat terus meningkatkan kinerja brand equity dan trust yang diterima oleh konsumen saat menggunakan alat berat excavator merek kobelco sehingga akan meningkatkan customer loyalty untuk menggunakan alat berat excavator merek kobelco di Kota Bandung sebagai alat berat yang menjadi pilihan para konsumennya. Penelitian ini juga diharapkan dapat menjadi dasar untuk dilakukannya penelitian lain mengenai customer loyalty tetapi dengan indikator serta objek yang berbeda.

Penelitian ini juga diharapkan dapat menjadi dasar untuk dilakukannya penelitian lain mengenai customer loyalty tetapi dengan indikator serta objek yang berbeda.

\section{DAFTAR PUSTAKA}

Aaker, A. David. 2008. Manajemen Ekuitas Merek, Alih bahasa oleh Aris Ananda. Jakarta: Mitra Utama.

Amaretta, Melinda and Evelyn Hendriana. 2011. The Effect of Marketing Communications and Price Promotion to Brand Equity. The $2^{\text {nd }}$ International Research Symposium in Service Management.

Arikunto, Suharsimi. 2010. Prosedur Penelitian Suatu Pendekatan Praktik. Yogyakarta:Bina Aksara

Assael H. (1998). Consumer Behavior and Marketing Action. First Ed. Boston: Kent Publishing Company.

Buchari Alma.(2009). Manajemen Pemasaran dan Pemasaran Jasa. Bandung: Alfabeta.

Baloglu, Seyhmus. (2009). Dimensions of Customer Loyaty: Separating Friends from Well Wishers. Cornell University

Chairani, Ebrahim, et al. 2012. Brand Performance and Brand Equity. Journal Of Contemporary Research In Business. Vol. 3 No.9. ijcrb.webs.com

Craven, D and Piercy, N. (2013). Strategic Marketing Nineth Ed. Singapore: McGraw-Hill Companise.Inc

Creswell, John W., alih bahasa oleh Achmad Fawaid. 2012. Research Design: Pendekatan Kualitatif, Kuantitatif, dan Mixed. Yogyakarta: Pustaka Pelajar
Dick, A. S., dan Basu, K. (1994). Customer Loyalty: Towards an Integrated Conceptual Framework. Journal of the Academy of Marketing Science, 22, 99-113.

Durianto, Darmadi. 2004. Strategi Menaklukan Pasar Melalui Riset Brand Equity dan Perilaku Merek. Jakarta:PT. Gramedia Pustaka Utama.

Elena Delgado-Ballester and Jose' Luis MunueraAlema'n. 2005. Does brand trust matter to brand equity. Journal of Product \& Brand Management 14/3 (2005). Emerald Group Publishing Limited [ISSN 1061-0421]

Fandy, Tjiptono. 2005. Brand Management. Yogyakarta:PT. ANDI Offset

2008. Brand Management \& Strategy. Yogyakarta:PT. ANDI Offset . 2009. Strategi Pemasaran. Yogyakarta:PT. ANDI Offset 2010. Strategi Pemasaran . Yogyakarta:PT. ANDI Offset.

Francois, A. Carrillat. (2009). Brand Management. SAGE Publications.

Fournier, Susan (1998). "Consumers and Their Brands: Developing Relationship Theory in Consumer Research". Journal of Consumer Research, 24 (4), March, 343-373

Ghorban, Zahra Sayed. 2012. Advertising and Brand Equity Creation: Examination of Product Market in Iran. International Journal of Business and Management Tomorrow Vol 2 No 7. IJBMT

Ghozali, Imam. 2015. Partial Least Square Konsep, Teknik dan Aplikasi Menggunakan Program SmartPLS 3.0. Semarang: Badan Penerbit Universitas Diponegoro

Griffin, Jill. (2011). Customer Loyalty: How to Earn It, How to Keep It. Mc Graw Hill, Kentucky

Hasan, Ali. (2013). Marketing dan Kasus-Kasus Pilihan. Yogyakarta: CAPS

Hair Jr., J. F; Black, W. C; Babin. B. J; Anderson. R. E. (1998). Multivariate Data Analysis, A Global Perspective, Ed 7. New Jersey: Pentice Hall, Pearson Education Inc.

Hermawan, Kartajaya. (2003). Marketing in Venus. Jakarta: MarkPlus.Inc

Hollensen, Svend. 2003. Marketing Management A Relationship Approach, Prentice Hall. Pearson Education Limited, England 
Hsu, Yen. (2011). Design innovation and marketing strategy in successful product competition. Journal of Business \& Industial Marketing, Vol 26 Issue 4 Pp. 223-236. Emerald Group Publishing Limited 0885-8624

Joreskog, G. K. (2002). Structural Equation Modeling with Ordinal Varaibels.

John Burnett dan Moriarty Sandra. 2011. Introduction to Marketing Communication. New Jersey: Pentice Hall.

Keller, Kevin L. 2013. Strategic Brand Management Global Edition. New Jersey: Pearson Education International.

Kotler, P and Armstrong, G. (2014). Principles of Marketing. New Jersey: Pearson Education.Inc

Kotler, P and Keller, K. (2012). Marketing Management. New Jersey: Pearson Education.Inc

Lassar, Walfried et al. 1995. Measuring costumer based brand equity. Journal of Consumer Marketing Vol. 12 No.4 1995 pp 11-19 (C) MCB University Press.

Lamb, Hair, Mcdaniel. (2011). Marketing. 11ed. USA: South-Western Cengage Learning.

Lee, Pui-Wan and Lau. (2003). The Role of Perceived Risk in New Product Alliances. PhD Dissertation. Washington State University.

Lovelock, Christopher H, Jochen Wirtz \& Patricia Chew. (2012). Essentials of Service Marketing. 2nd Edition. Singapore: Pretince Hall Published.

Maholtra, Narkesh K. 2010. Riset Pemasaran, Penerapan Terapan. Jakarta: Gramedia Pustaka Utama.

Mick, D.G. and DeMoss, M. (1990), Self-gifts: phenomenological insights from four contexts, Journal of Consumer Research, Vol. 17 No. 3, pp. 322-332.

Morais, Duarte B. (2005). Fostering Loyal Customer Relationship. University Park: School of Restaurant and Recreation Management.

Mowen JC and Minor M. (1998). Consumer Behavior. Fifth Ed. New Jersey: Prestice Hall, Inc.

Nafiseh, Sedaghat et.al. 2012. The Impact of Promotional Mix Elements on Brand Equity. American Journal of Scientific Research. ISSN 1450-223X Issue 43, pp 5-15. Euro Journals Publishing Inc.
2009. Basic Marketing Research. $3^{\text {th }}$ edition. New Jersey: Prentice Hall.

Netemeyer et al. 2004. Developing and validiting measures of facets of costumer based brand equity. Journal of Business Research 57 (2004) 209-224 Prentice Hall.Inc

Oliver. (2005). Whence Consumer Loyalty: Journal of Marketing (Special Issue), 63, 33-44.

Oliver, Richard L. (2008). Satisfaction, A Behavioral Perspective on The Consumer International Ed. New York: McGraw Hill

Oliver, Richard L. (1993) Assessing the Dimensionality and Structure of the Consumption Experience: Evaluation, Feeling, and Satisfaction. Journal of Consumer Research. 20 (December), hal. 451-466. 1993.

Parasuraman, A. (2008). SERQUAL: A Multi-Item Scale for Measuring Consumer Perceptions of Service Quality. Journal of Retailing, Vol. 64, p. 31-43

Park, W.C., MacInnis, D.J., Priester, J.R., Eisingerich, A.B. and Iacobucci, D. (2010), Brand attachment and brand attitude strength: conceptual and empirical differentiation of two critical brand equity drivers, Journal of Marketing, Vol. 74 No. 6, pp. 1-17

Park, W.C., Macinnis, Deborah J., and Priester, J.R. (2006). Beyond Attitudes: Attachment and Consumer Behavior. Seol Journal of Business, Vol. 12 No. 2

Rahmani, Zeinolabedin, et.al. 2012. Review the Impact of Advertising and Sale Promotion on Brand Equity. Journal of Business Studies Quarterly. Vol 4, No 1, pp 64-73. ISSN 2152-1034

Roy, Rajat and Ryan Chau. 2011. Consumer-based brand equity and status-seeking motivation for a global versus local brand. Asia Pacific Journal of Marketing and Logistic, Vol. 23 No. 3, 2011 pp. 270-284

Schiffman, Leon G and Kanuk, Lesli L. (2010). Consumer Behavior 10 ed. Pearson Prentice Hall

Seyhmus, Baloglu. (2009). Dimensions of Customer Loyalty: Separating Friends from Well Wishers. Cornell Hotel and Restaurant Administration Quarterly, Cornell University.

Slater, J.S. (2001), Collecting brand loyalty: a comparative analysis of how Coca-Cola and Hallmark use collecting behaviour to 
enhance brand loyalty, in Mary, C.G. and Joan, M.-L. (Eds), NA - Advances in Consumer Research, Vol. 28, Association for Consumer Research, Valdosta, GA, pp. 362369.

Smith, Jan. (2002). Customer Service as a Product, Handbook of Customer Service. Gower Publishing Limited.

So, Jing-Theng. (2013). Corporate branding, emotional attachment, and brand loyalty: the case of luxury fashion branding. Journal of Fashion Marketing and Management. Vol. 17 No. 4, pp. 403-423.

Sugiyono. 2010. Metode Penelitian Bisnis. Bandung: Alfabeta

Susanti, Vivid dan Cholicul Hadi. 2013. Kepercayaan Konsumen dalam Melakukan Pembelian Gadget secara Online. Jurnal Psikologi Industri dan Organisasi Vol 02. No. 01

Taylor, Steven A, Kevin Celuch dan Stephen Goodwin. 2004. The importance of brand equity to customer loyalty. Journal of Product \& Brand Management Volume 13 .
Number 4 • 2004 · pp. 217-227 q Emerald Group Publishing Limited

Thomson, M. (2005). The Ties That Bind: Measuring the Strength of Consumers' Emotional Attachment to Brands. Journal of Consumer Psychology, 15(i), 77-91. Lawrence Erlbaum Associates, Inc.

Tjiptono, Fandy. (2005). Brand Management \& Stategy. Yogyakarta: CV. Andi

Tjiptono, Fandy. (2008). Strategi Pemasaran. Yogyakarta: CV. Andi

Valentina, S et.al. (2013). Customer Loyalty Development: The Role Of Switching Cost. France: ESSCA School of Management, LUNAM University

Wulf, Gaby, and Lacobucci. (2001). Marketing Research: Methodological Foundations. $9^{\text {th }}$ Ed. Mason, Ohio: Thomson/South-Western

Zeithaml, Valerie A. (2013). Customer Contributions and Roles in Service Delivery. North Carolina: University of North Carolina 